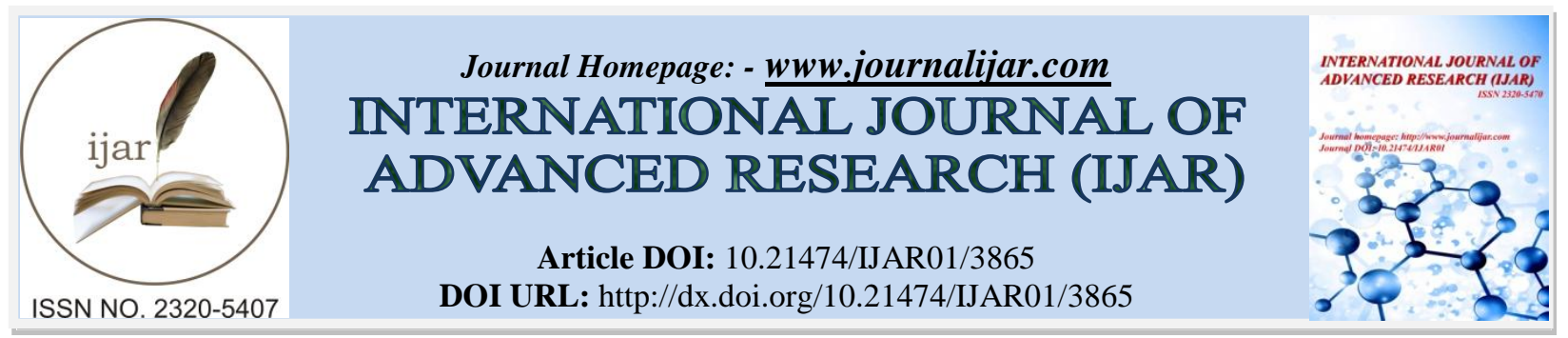

RESEARCH ARTICLE

\title{
CORRELATION OF ANTI-THYROID PEROXIDASE ANTIBODIES (ANTI-TPO) WITH THYROID HORMONES IN LOCAL POPULATION OF WESTERN NEPAL.
}

\author{
Sachin Dhakal ${ }^{1}$, Amar Nagila ${ }^{2}$, Reetu Koirala ${ }^{3}$, Mahendra Prasad Bhatta ${ }^{2}$, Sanjib Mani Regmi ${ }^{2}$, Alneil M. \\ Hamza $^{4}$ and Dipendra Raj Pandeya ${ }^{4,5}$ \\ 1. Department of Medicine, Western regional Hospital. Pokhara, Nepal. \\ 2. Gandaki Medical College and Teaching Hospital Pvt. Ltd. Pokhara, Nepal. \\ 3. Charak Academy, Pokhara, Nepal. \\ 4. College of Applied Medical Sciences, Al Jouf University, Al Qurayyat, Saudi Arabia. \\ 5. Department of Biochemistry, Nepalese Army Institute of Health Sciences, Kathmandu, Nepal.
}

\section{Manuscript Info}

Manuscript History

Received: 08 February 2017

Final Accepted: 05 March 2017

Published: April 2017

Key words:-

Auto immune thyroiditis, Thyroid

stimulating hormone, Tri-iodothyronine,

Thyroxine, Anti-TPO

\section{Abstract}

Background: Thyroid disorders are more common in Nepalese population. Thyroid autoimmunity can cause several forms of thyroid disorders ranging from hypothyroidism to hyperthyroidism. Anti-TPO $\mathrm{Ab}$ has emerged as the most generally useful marker for the diagnosis and management of autoimmune thyroid disease.

Objective: This study was undertaken to investigate the association between Anti-TPO antibody and thyroid dysfunction in population of western Nepal

Material and Methods: A hospital-based cross-sectional study involving 100 patients was conducted in the Department of Medicine, Gandaki Medical College and Teaching Hospital Pvt. Ltd. Pokhara, Nepal, Nepal during December 2015 to June 2016. Patient's data collection and relevant laboratory test [serum fT3, fT4, TSH and Anti TPO] were performed in the Department of Laboratory, Gandaki Medical College and Teaching Hospital. Thyroid abnormalities were diagnosed on the basis of these laboratory results. All the parameters were measured using CLIA method (DiaSorin Liaison @ R Instrument). Results: The prevalence of the abnormal anti-TPO antibody is $25.93 \%$ in male and $74.07 \%$ in female group was noticed. The anti-TPO prevalence was higher in females than in males. In addition, Anti-TPO antibody has statistical significant correlation with TSH and fT4 but not with fT3.

Conclusion: In conclusion, our study demonstrates that in autoimmune thyroiditis is more common in Nepalese females then men. This confirms the correlation between thyroid hormones and Anti-TPO antibody.

Copy Right, IJAR, 2017,. All rights reserved.

Corresponding Author:- Dr. Dipendra Raj Pandeya

1. Address:- College of Applied Medical Sciences, Al Jouf University, Al Qurayyat, Saudi Arabia. 
Thyroid hormones were recognized as one of the most important regulatory hormones and modulate every component of the metabolic pathways [1]. Thyroid dysfunction is prevalent in clinical practice and has significant consequences. An autoimmune thyroid disease (AITD) is by far the most frequent cause of Hypothyroidism and is characterized by the presence of antithyroid antibodies. Autoimmune thyroid diseases are common organ-specific autoimmune disorders mostly seen in women 30-50 years old [2]. It occurs due to loss of tolerance to autoantigens thyroid peroxidase (TPO), thyroglobulin (Tg), thyroid stimulating hormone receptor (TSH-R) which leads to the infiltration of the gland. Thyroid autoimmunity can cause several forms of thyroid disorders but Hashimoto thyroiditis and Graves' disease are the most common types and share many features [3]. Approximately $2 \%$ of the female and $0.2 \%$ of the male population are affected with AITD and the prevalence increases with advanced age [4]. There are a number of auto antibodies associated with the autoimmune thyroid diseases. Two common antibodies that cause thyroid problems are directed against thyroid cell proteins: thyroid peroxidase and thyroglobulin. Thyroid peroxidase (TPO) was first discovered as a thyroidal microsomal autoantigen by Belyavin and Trotter in 1957 [5]. TPO-Abs are present in much higher titers than $\mathrm{Tg}-\mathrm{Ab}$. Measuring levels of thyroid antibodies may help diagnose the cause of the thyroid problems. Thyroid peroxidase (TPO) antibodies are one of the major secondary antibodies associated with autoimmune thyroid disease. TPO antibodies (TPO-Abs) appear to be involved in the tissue destructive processes associated with the hypothyroidism observed in Hashimoto's and atrophic thyroiditis [6]. Evaluation of the diagnostic value of an anti-TPO assay in patients with different types of thyroid disease and in controls showed increased anti-TPO antibodies in $>90 \%$ patients with active autoimmune thyroiditis [7, 8]. Measurement of this autoantibody is useful for settling the diagnostic quandary demonstrated by the evident inconsistency between thyroid function test parameters.

In the developed world, thyroid autoimmunity is the main cause of hypothyroidism, which itself results in poor obstetric outcomes. Even in women with biochemically normal thyroid function, studies have reported an association between the presence of thyroid autoantibodies, particularly thyroid peroxidase antibodies and adverse pregnancy outcomes, including miscarriage, preterm birth, and adverse neurodevelopmental sequelae in children [9]. The prevalence of thyroid autoantibodies varies between populations and is influenced by many factors including as heredity and the environment $[\mathbf{1 0}, \mathbf{1 1}]$. Thyroid dysfunction and autoimmunity are relatively common in women of reproductive age group and has been associated with various adverse pregnancy outcomes.

A better understanding of the strong effect of thyroid hormonal status on host physiology will modify health care providers to make decisions regarding thyroid hormone evaluation and therapy in concert with evaluating and treating metabolic disorders. There is less data on thyroid dysfunction, antibody status and magnitude of thyroid disorders from Nepal. A proper study regarding the various aspects of thyroid problem such as pattern of thyroid disorders and autoimmunity in adults would be helpful to understand this health problem better. The goal of this study is to access the understanding of the effects of Anti-TPO antibodies on thyroid hormones level and would help in elucidating its probable pathogenetic role in induction of hypo- or hyperthyroidism in local population of western Nepal.

\section{Material and Methods:-}

Anti-TPO, thyroid hormones and TSH were determined in 100 selected individuals, presented to the out-patient department of Medicine, Gandaki Medical College and Teaching Hospital Pvt. Ltd. Pokhara, Nepal. The study period was Dec 2015 to June 2016 and it's a cross-sectional study. The age and sex of the patients were also recorded.

The concern was obtained from the participants before the commencement of the study. Blood sample were collected aseptically. A total of $5 \mathrm{ml}$ of venous blood was drawn from each subject. Blood samples were then centrifuged at $2000 \mathrm{rpm}$ for $10 \mathrm{~min}$ in a refrigerated centrifuge to separate serum samples from the cells. Serum levels of triiodothyronine (fT3), thyroxine (fT4), thyroid-stimulating hormone (TSH), anti-thyroid peroxidase antibodies (anti-TPO ab) were measured using CLIA method ( Diasorin Liaison @R Instrument), where the normal references ranges for these tests were $\mathrm{fT} 4=0.89-1.76 \mathrm{ng} / \mathrm{dL}, \mathrm{fT} 3=2.30-4.20 \mathrm{pg} / \mathrm{ml}, \mathrm{TSH}=0.35-5.50 \mathrm{mIU} / \mathrm{L}$, anti-TPO $=0-35 \mathrm{IU} / \mathrm{mL}$ respectively.

\section{Statistical Analysis:-}

The study data was analyzed by using SPSS program to compute descriptive parameters including mean and frequencies, and inferential statistics was used including student's $t$ test to test the significance of the differences between the mean values of two continuous variables and Chi-squire test (X2) test the difference in proportions 
categorical variables between two groups. The level of confidence $(P<0.05)$ was considered as cutoff value for significance.

\section{Results:-}

Table 1: shows the age categories for 100 patients (20 males and 80 females) that were enrolled in this study. The highest percentage of age distribution (50\%) was observed in a group of $>40 \mathrm{yrs}$, and the remaining for the other three groups.

Table 2: shows that the mean age of the males was 47.9 \pm 13.4 years (range 30-78) and 40.4 \pm 13.7 years (range 3-73) for females with statistical significant difference, $\mathrm{P}=0.031$. Also, Thyroid function tests (fT3, fT4, TSH and AntiTPO) were studied to assess hypothyroidism status among the gender types of the patients. The results were compared between males and females which were found to be $(3.0 \pm 2.4$ and $2.8 \pm 0.8),(0.91 \pm 0.66$ and $0.97 \pm 0.35)$, $(17.8 \pm 27.1$ and $9.9 \pm 17.4)$ and $(228.6 \pm 251.6$ and $142.49 \pm 285.6)$ respectively with no statistical significance $\mathrm{P}>0.05$ for all parameters.

Table 3: shows the percentage of abnormal thyroid function tests results that compared between male and female were found to be for fT3 $(25 \%$ vs $23 \%, \mathrm{P}=0.177)$ with no statistical significance . For the others (fT3, fT4 and AntiTPO) the compared results were found to be $(40 \%$ vs $16 \%, \mathrm{P}=0.010),(90 \%$ vs $63 \%, \mathrm{P}=0.048)$ and $(47 \%$ and $44 \%$, $\mathrm{P}=0.027$ ) respectively, with statistical significance difference $\mathrm{P}<0.05$ for three parameters.

Table 4: shows that percentage of abnormal result within study subjects for male and female base on the age category (<40 year and > 40 year). For fT3 the abnormal results within less than 40 years category were $(0 \%$ vs $50 \%)$ in comparison with $(100 \%$ vs $50 \%)$ in more than 40 years category with statistical significance difference $\mathrm{p}=$ 0.042. For (fT4, TSH and Anti-TPO) the comparison results between age categories were found to be not statistically significance $\mathrm{P}>0.05$ for all parameters. In addition number of gender type for each age category was depicted in (figure 1)

Table 5: shows the relationships between Anti-TPO and thyroid hormone (fT3, fT4 and TSH). For T3 the result was found to be a negative relationship $(\mathrm{r}=-0.190, \mathrm{n}=100, \mathrm{p}=0.058)$ which was no statistically significant depicted in figure 2. For fT4 also, the result indicate there was negative relationship which is statistically significant $(\mathrm{r}=-0.376$, $\mathrm{p}=<0.001)$ depicted in figure 3 . TSH result present statistically significant positive linear relationship $(\mathrm{r}=-0.671, \mathrm{p}$ $=<0.001)$ depicted in figure 4

Table 1:- Percentage of age groups among study group

\begin{tabular}{|c|c|c|c|c|}
\hline Age category & Male $(\mathrm{n}=20)$ & Female $(\mathrm{n}=80)$ & Total & $\%$ \\
\hline$\leq 20$ & 0 & 7 & 7 & $7 \%$ \\
\hline $21-30$ & 1 & 10 & 31 & $11 \%$ \\
\hline $31-40$ & 6 & 25 & 51 & $31 \%$ \\
\hline$>40$ & 13 & 38 & 100 & $51 \%$ \\
\hline Total & 20 & 80 & & $100 \%$ \\
\hline
\end{tabular}

Table 2:- Comparison of studied TFTs biochemical parameters of study group

\begin{tabular}{|c|c|c|c|}
\hline \multirow{2}{*}{$\begin{array}{c}\text { TFTs } \\
\text { Parameters }\end{array}$} & Male $(n=20)$ & Female $(n=80)$ & \multirow[t]{2}{*}{ P- value } \\
\hline & \multicolumn{2}{|c|}{ Means \pm SD (Range) } & \\
\hline Age, years & $47.9 \pm 13.4(30-78)$ & $40.4 \pm 13.7(3-73)$ & 0.031 \\
\hline fT3 & $3.0 \pm 2.4(1.3-13.0)$ & $2.8 \pm 0.8(0.73-7.82)$ & 0.460 \\
\hline fT4 & $0.91 \pm 0.66(0.0-3.5)$ & $0.97 \pm 0.35(0.15-3.1)$ & 0.555 \\
\hline $\mathrm{TSH}$ & $17.8 \pm 27.1(0.0-99.1)$ & $9.9 \pm 17.4(0.0-112)$ & 0.232 \\
\hline Anti-TPO & $228.6 \pm 251.6(8-757)$ & $142.49 \pm 285.6(0.0-1644)$ & 0.222 \\
\hline
\end{tabular}


Table 3:- Comparison between percentage of abnormal TFTs results and gender.

\begin{tabular}{|l|c|c|c|c|c|c|}
\hline \multirow{2}{*}{$\begin{array}{c}\text { TFTs } \\
\text { Parameters }\end{array}$} & \multicolumn{2}{c|}{ Male $(\mathrm{n}=20)$} & \multicolumn{2}{c|}{ Female $(\mathrm{n}=80)$} & \multirow{2}{*}{$\chi^{2}$ P-value } \\
\cline { 2 - 6 } & Normal & Abnormal & Normal & Abnormal & & \\
\hline fT3 & 15 & $5(25 \%)$ & 62 & $18(23 \%)$ & 1.82 & 0.177 \\
\hline TSH & 12 & $8(40 \%)$ & 67 & $13(16 \%)$ & 6.54 & 0.010 \\
\hline Anti-TPO & 2 & $18(90 \%)$ & 30 & $50(63 \%)$ & 3.88 & 0.048 \\
\hline \multicolumn{2}{|l|}{$P$ value based on chi squire test $(p<0.05)$ significant } & 40 & $40(50 \%)$ & 4.83 & 0.027 \\
\hline
\end{tabular}

Table 4:- comparison between percentage of abnormal values and age categories

\begin{tabular}{|c|c|c|c|c|c|c|}
\hline \multirow{2}{*}{$\begin{array}{c}\text { TFTs } \\
\text { Parameters }\end{array}$} & \multicolumn{2}{|c|}{ Less than 40 year } & \multicolumn{2}{|c|}{ More than 40 year } & \multirow[t]{2}{*}{$\chi^{2}$} & \multirow[t]{2}{*}{ P- value } \\
\hline & Male & Female & Male & Female & & \\
\hline fT3 & $0(0 \%)$ & $9(50 \%)$ & $5(100 \%)$ & $9(50 \%)$ & 4.11 & 0.042 \\
\hline fT4 & $1(13 \%)$ & $3(23 \%)$ & $7(87 \%)$ & $10(77 \%)$ & 0.36 & 0.548 \\
\hline $\mathrm{TSH}$ & $5(28 \%)$ & $24(48 \%)$ & $13(72 \%)$ & $26(52 \%)$ & 2.21 & 0.136 \\
\hline Anti-TPO & $4(29 \%)$ & $18(45 \%)$ & $10(71 \%)$ & $22(55 \%)$ & 1.16 & 0.281 \\
\hline
\end{tabular}

Table 5: Correlation between Anti-TPO and thyroid hormones within study group

\begin{tabular}{|c|c|c|c|}
\hline Thyroid hormones & $\mathrm{r}$ & $\mathrm{R}^{2}$ & P-value \\
\hline fT3 & -0.190 & 0.036 & 0.058 \\
\hline fT4 & -0.376 & 0.141 & $<0.001$ \\
\hline fTSH & 0.671 & 0.451 & $<0.001$ \\
\hline
\end{tabular}

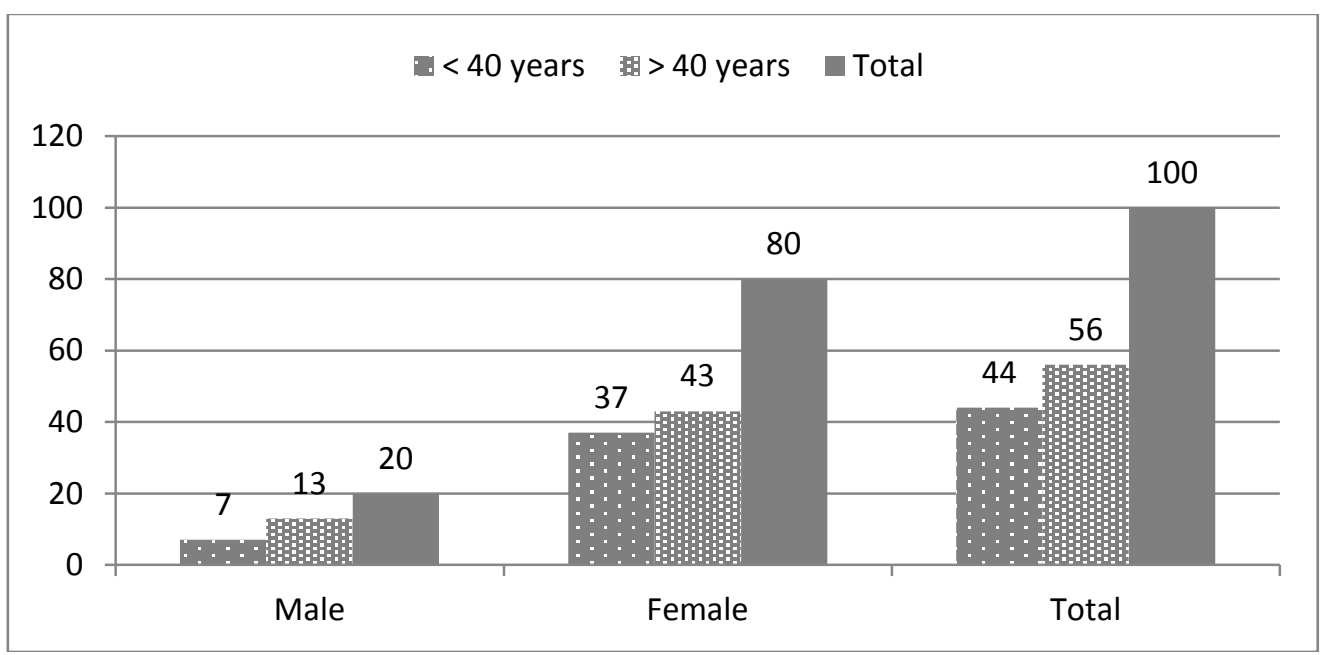

Figure 1:- Association between number of gender type and age category 


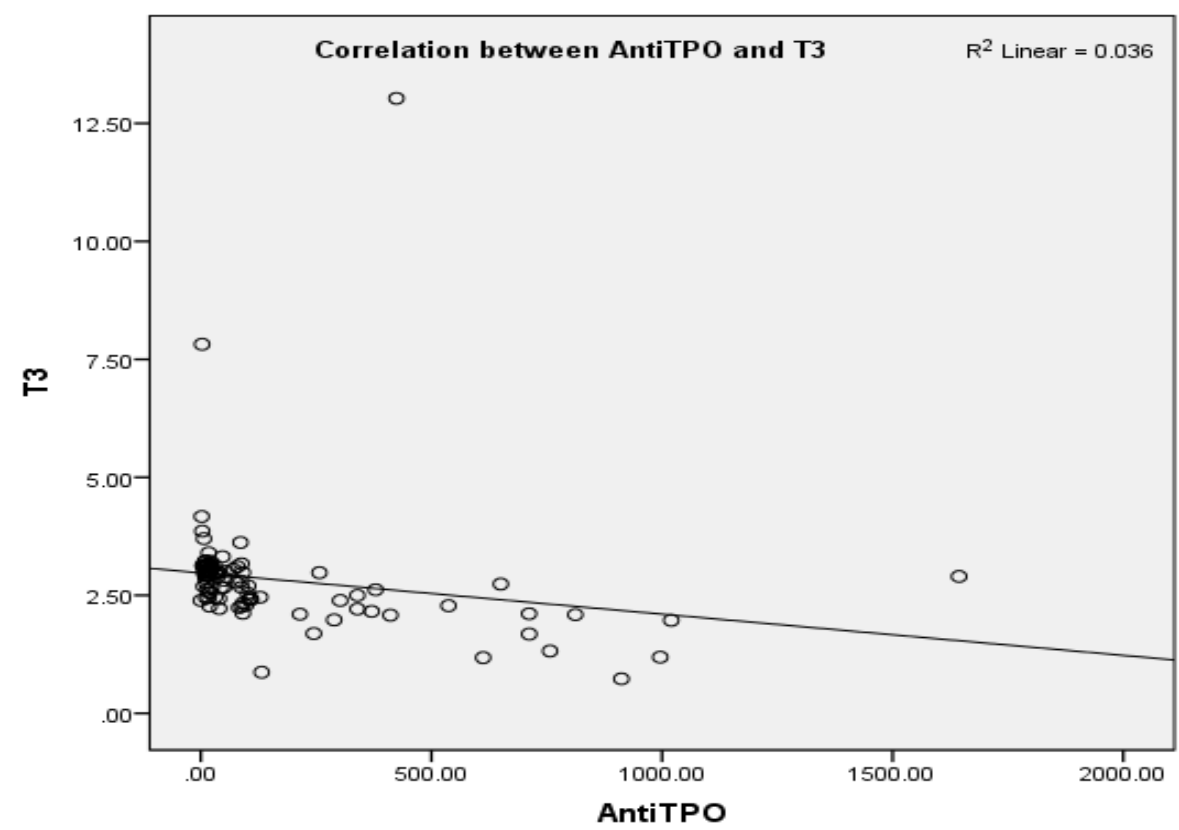

Figure 2:- Correlation between Anti-TPO and $\mathrm{T}_{3}$

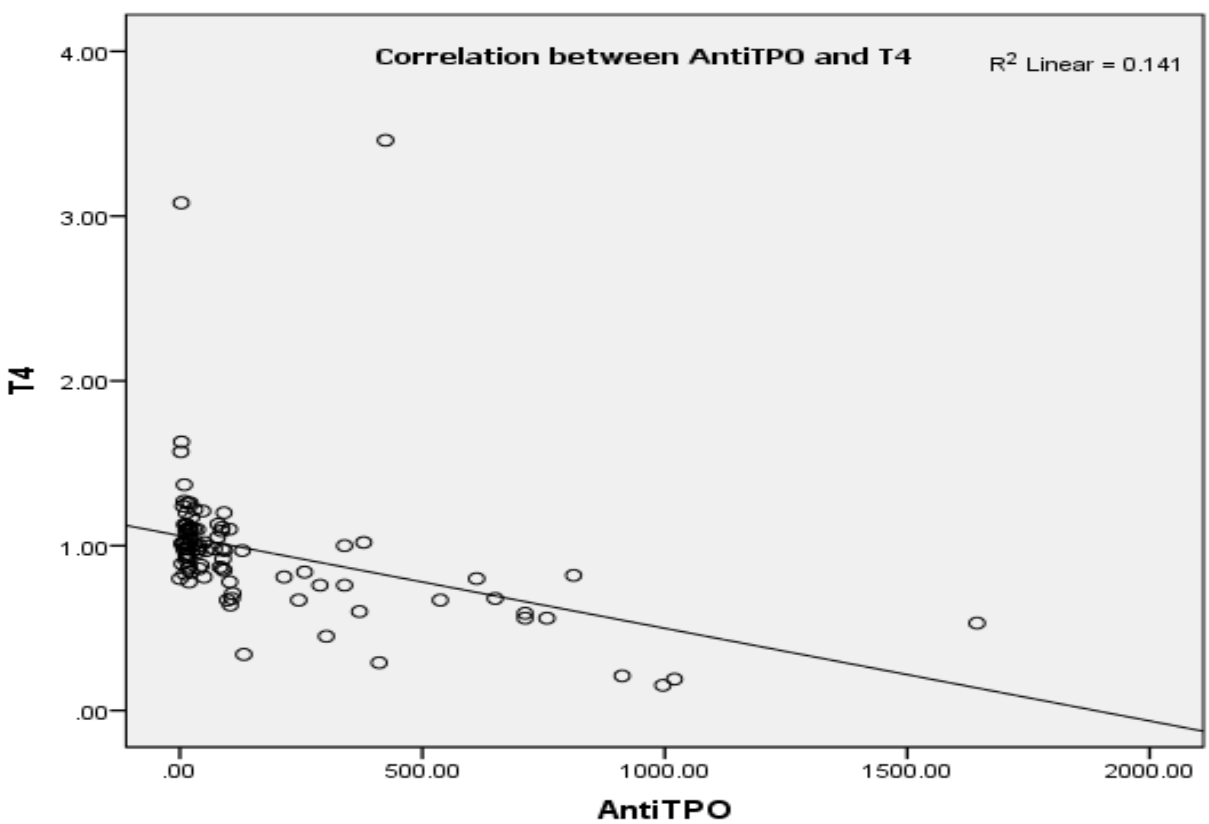

Figure 3:- Correlation between Anti-TPO and $\mathrm{T}_{4}$ 


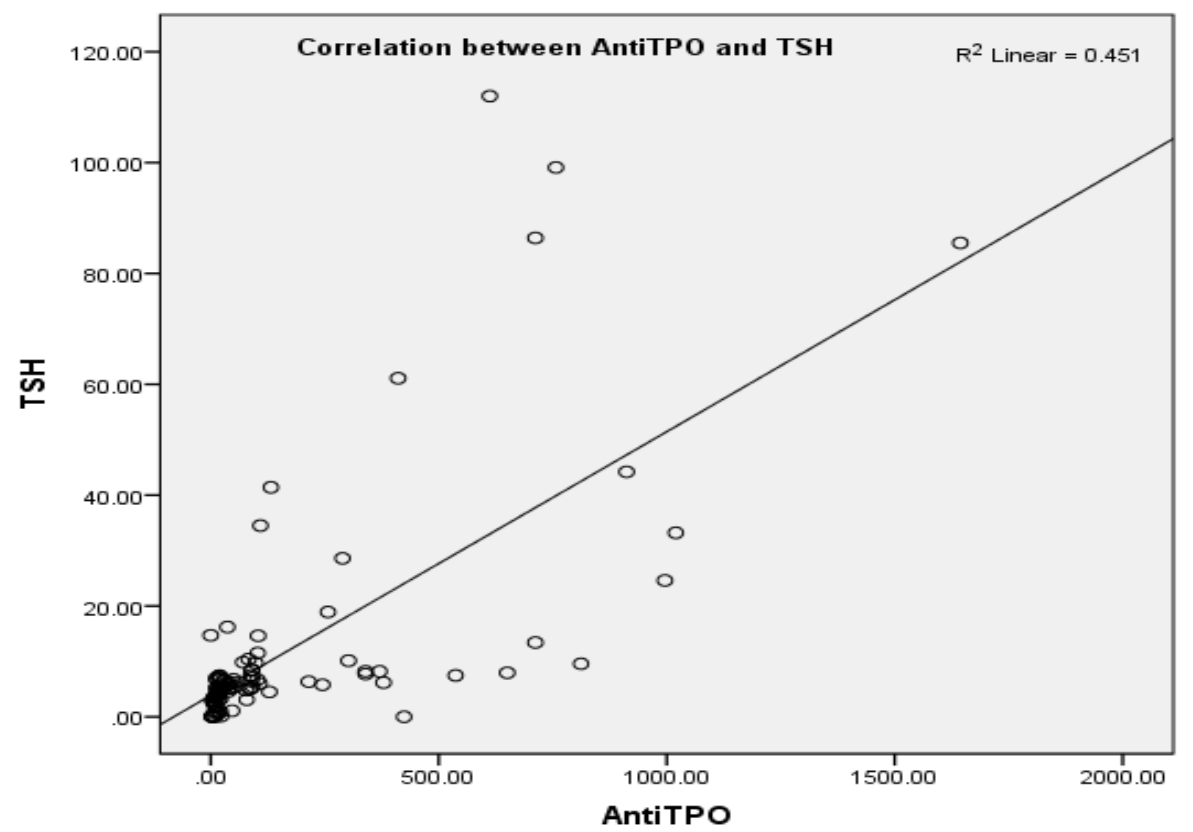

Figure 4:- Correlation between Anti-TPO and TSH

\section{Discussion:-}

In the recent years anti-TPO antibodies are witness closely associated with the activity of autoimmune thyroiditis [12]. The pathogenic role and the diagnostic value of anti-TPO antibody have been evaluated in thyroid cellular dysfunction and in the pathogenesis of hypothyroidism [13]. Detection of these antibodies in significant titers helps in planting the etiology of both hypo and hyper functioning thyroid diseases [14]. The higher the TPO-Abs the more rapid the failure of thyroid. To validate these claims, present study has been proposed. In this regard, it was well established that anti-TPO is an important diagnostic tool regarding determination of disease activity of thyroiditis, and assessment of treatment progress and clinical outcomes.

The results of our study show that $54 \%$ of patients with high anti-TPO were between 3-78 years old and 40 out of the 54 patients, $74.07 \%$ were female patients and had elevated anti-TPO. It is seen in this study that the prevalence of anti-TPO in females is more than males and this confirms that women are affected more by autoimmune thyroid diseases than men. This finding is similar with the study done by Canaris et al.[15], which mentioned that autoimmune thyroid diseases affect women 2 to 4 times more than men. In addition, Mohanty et al. [16] showed that 45 of the 61 subclinical hypothyroid patients had elevated anti-TPO $(73.78 \%)$, this finding also be in accord with our study. In agreement with our study Swain et al. has also reported that most (95\%) of the patients with autoimmune thyroid disease were women, mainly belonging to the age group of 30-50 years [2].

Consistent with previous research, in the present study, thyroid autoantibodies were significantly more prevalent in female than in male participants. Literature studies suggest a constant increase in the prevalence of anti-TPO positive patients in Nepal.

The results for different age groups involved in this study are shown in Table 1 . The mean age of the males and females groups were noticed with statistical significant difference, where the average age of the male were $47.9 \pm 13.4$ years and for females $40.4 \pm 13.7$ years. In this study, most of the thyroid disorder was noticed in $>40$ years of age groups and females are more vulnerable to hypothyroidism (52\%). This agrees with some previous studies that hypothyroidism was more prevalent $(40.5 \%)$ in the age group of 36-45 years with obvious female preponderance [17].

In most cases with $\mathrm{T}_{3}, \mathrm{~T}_{4}, \mathrm{TSH}$ and Anti TPO antibody abnormality were observed in the $>40$ years age group. For instance, hypothyroidism is far more common among elderly women than among other groups, particularly in the presence of thyroid autoantibodies $[\mathbf{4}, \mathbf{1 8}]$. However, the results of thyroid function test parameters $\left(\mathrm{T}_{3}, \mathrm{~T}_{4}, \mathrm{TSH}\right.$ and 
Anti-TPO) between two groups had no statistical significance $(\mathrm{P}>0.05)$ for all parameters. Similarly, the number of subjects with who had abnormal $\mathrm{T}_{3}, \mathrm{~T}_{4}$, TSH and anti-TPO were significantly different in both groups $(\mathrm{p}<0.05)$ except T3 $(p<0.177)$.This is likely a result of the small number of participating males $(n=20)$ and different population characteristics. A similar observation was found in a health survey in Norway, in which the prevalence of pathological anti-TPO was $13.9 \%$ in females and $2.8 \%$ in males.

In our study, T4 $(r=-0.376, p=<0.001)$ had negative significant correlation and TSH $(r=0.671, p=<0.001)$ had a significant positive correlation with anti TPO using Pearson's' correlations. On the other hand, T3 had negative relationship $(r=-0.190, p=0.058)$ which was no statistically significant. There is a significant correlation between hypothyroidism and Anti TPO Antibody. This is also consistent with previous study by Ghoraishian et al. reported significant correlation between TSH and T4 concentration and elevated anti-TPO antibody was demonstrated [19]. In addition, similar study done in Greece reported significant association between sub-clinical hypothyroidism and positive anti-thyroid antibodies [20, 21]. These findings were compatible to the results reported by [22] who found that proportional correlation was noticed between anti-TPO and (AITD) marker particularly TSH. Serum TSH concentration are considered the most reliable indicator of thyroid function abnormalities, and TSH analysis stands as the primary means of study thyroid function. On the other hand, our study was contradicted with previous studies [23] they mentioned, there were no relationship between serum TSH concentration and anti-TPO-Ab also no association between thyroid hormones (T3, T4) and anti-TPO-Ab.

\section{Conclusion:-}

Finally, we conclude that anti-TPO assessment is a necessary test for patients who have high levels of TSH or low levels of T3 and T4, for diagnosis of autoimmune hypothyroidism, which suggests a direct pathogenetic role for anti-TPO in development of hypothyroidism. Anti-TPO antibodies can be used as a alternate marker and establishing the etiological diagnosis of autoimmune thyroid diseases in population.

\section{References:-}

1. Crunkhorn S, Patti ME. Links between thyroid hormone action, oxidative metabolism, and diabetes risk? Thyroid. 2008;18:227-37.

2. Swain M, Swain T, Kumar Mohanty B. Autoimmune thyroid disorders-an update. Indian Journal of Clinical Biochemistry. 2005;20:9-17.

3. Marcocci, C. and L. Chiovato, 2000. Thyroid-directed antibodies. In: Braverman, L.E. and R.D. Utiger. The Thyroid: A fundamental and clinical text. 8th Edn. Philadelphia: Williams and Wilkins, pp: 414-31.

4. Canaris GJ, Manowitz NR, Mayor G, Ridgway EC. The Colorado thyroid disease prevalence study. Arch Intern Med.2000;160:526-34.

5. Belyavin G, Trotter, WR. Investigation of thyroid antigens reacting with Hashimoto sera: evidence for an antigen other than thyroglobulin. Lancet. 1959; 648.

6. Seyed Mahmood Ghoraishian, Seyed Hossein Hekmati Moghaddam and Mohammad Afkhami. Relationship Between Anti-Thyroid Peroxidase Antibody and Thyroid Function Tests.W J Med Sci. 2006; 1(1):44-7.

7. Engler H, Riesen WF, Keller B. Diagnostic value of autoantibodies against microsomal thyroid peroxidase (anti-TPO). Schweiz Med Wochenschr. 1992;122:1976-80.

8. Laurberg P, Pedersen KM, Vittinghus E, Ekelund S. Sensitive enzyme-linked immunosorbent assay for measurement of autoantibodies to human thyroid peroxidase. Scand J Clin Lab Invest. 1992;52:663-9.

9. Glinoer D, Delange F. The potential repercussions of maternal, fetal, and neonatal hypothyroxinemia on the progeny. Thyroid. 2000;10:871-87.

10. Brix TH, Hansen PS, Kyvik KO, et al. Aggregation of thyroid autoantibodies in first-degree relatives of patients with autoimmune thyroid disease is mainly due to genes: a twin study. Clin Endocrinol (Oxf). 2004; 60: 329-34.

11. Prummel MF, Strieder $\mathrm{T}$ and Wiersinga WM. The environment and autoimmune thyroid diseases. Eur $\mathbf{J}$ Endocrinol. 2004; 150: 605-18.

12. Rapoport B. Pathophysiology of Hashimoto-thyroiditis and hypothyrodism.Annu Rev Med. 1991;42:91-6.

13. Weetman AP, McGregor AM. Autoimmmune thyroid disease: further developments in our understanding. Endocr Rev. 1994;15:788-814.

14. Chiovato L, Bassi P, Santini F, Mammoli C, Lapi P, Carayon P, et al.Antibodies producing complementmediated thyroid cytotoxicity in patients with atrophic or goitrous autoimmune thyroiditis. J Clin Endocrinol Metab. 1993;77:1700-5. 
15. Canaris GJ, Manowitz NR, Mayor G, Ridgway C. The Colorado thyroid disease prevalence study. Arch Intern Med. 2000; 160: 526-34.

16. Mohanty S, Amruthlal W, Reddy GC, Kusumanjali G, Kanagasabapathy AS, Rao P. Diagnostic strategies for subclinical hypothyroidism. Indian J Clin Biochem. 2008;23(3):279-82.

17. Saha P k, Baur. B, Gupta S.Thyroid stimulating hormone measurement as the confirmatory diagnosis of hypothyroidism: A study from a tertiary-care teaching Hospital, Kolkatta. Indian J Community Med. 2007; 32:139-40.

18. Tunbridge WM, Evered DC, Hall R, Appleton D, Brewis M, Clark F. The spectrum of thyroid disease in a community: the Whickham Survey. Clin Endocrinol (Oxf) 1997;7(8):481-93.

19. Ghoraishian SM, Moghaddam SH, AfkhamiArdekani M. Relationship between anti-thyroid peroxidase antibody and thyroid function test. Iran J Immunol 2006; 3:146-9.

20. Zois C, Stavrou I, Kalogera C, Svarna E, Dimoliatis I, Seferiadis K, et al. High prevalence of autoimmune thyroiditis in schoolchildren after elimination of iodine deficiency in North-western Greece. Thyroid 2003;13:485-9.

21. Jaksic J, Dumic M, Filipovic B, Ille J, Cvijetic M, Gjuric G. Thyroid diseases in a school population with thyromegaly. Arch Dis Child 1994; 70:103- 6.

22. Vlaeminck-Guillem V, Ho SC, Rodien P, Vassart G, Costagliola S. Activation of the cAMP pathway by the TSH receptor involves switching of the ectodomain from a tethered inverse agonist to an agonist. Molecular Endocrinology. 2002;16:736-46.

23. Benhadi N, Wiersinga WM, Reitsma JB, Vrijkotte TG, Van der Wal MF, Bonsel GJ Ethnic differences in TSH, T3, T4 concentrations or TPO antibodies. Clin Endocrinol (Oxf). .2007; 66(6): 765-70. 